\title{
Article
}

\section{An Electrochemical Sensor Based on Gold and Bismuth Bimetallic Nanoparticles Decorated L-Cysteine Functionalized Graphene Oxide Nanocomposites for Sensitive Detection of Iron Ions in Water Samples}

\author{
Na Zhou ${ }^{1}$, Jing $\mathrm{Li}^{2}$, Shaoxia Wang ${ }^{2}$, Xuming Zhuang ${ }^{2, *} \mathbb{D}$, Shouqing $\mathrm{Ni}^{3}$, Feng Luan ${ }^{2}, \mathrm{Xuran}_{\mathrm{Wu}}{ }^{2}$ and \\ Shunyang $\mathrm{Yu}^{1, *}$ \\ 1 Shandong Key Laboratory of Coastal Environmental Processes, Yantai Institute of Coastal Zone Research, \\ Chinese Academy of Sciences, Yantai 264003, China; nzhou@yic.ac.cn \\ 2 College of Chemistry and Chemical Engineering, Yantai University, Yantai 264005, China; \\ 1j508837@163.com (J.L.); 18865557620@163.com (S.W.); fluan@sina.com (F.L.); ytdxwxr@126.com (X.W.) \\ 3 Shandong Provincial Key Laboratory of Water Pollution Control and Resource Reuse, School of \\ Environmental Science and Engineering, Shandong University, Qingdao 266237, China; sqni@sdu.edu.cn \\ * $\quad$ Correspondence: xmzhuang@iccas.ac.cn (X.Z.); syyu@yic.ac.cn (S.Y.)
}

Citation: Zhou, N.; Li, J.; Wang, S.; Zhuang, X.; Ni, S.; Luan, F.; Wu, X.; $\mathrm{Yu}, \mathrm{S}$. An Electrochemical Sensor Based on Gold and Bismuth Bimetallic Nanoparticles Decorated L-Cysteine Functionalized Graphene Oxide Nanocomposites for Sensitive Detection of Iron Ions in Water Samples. Nanomaterials 2021, 11, 2386 https://doi.org/10.3390/nano11092386

Academic Editor: Abdelhamid Elaissari

Received: 21 August 2021

Accepted: 9 September 2021

Published: 14 September 2021

Publisher's Note: MDPI stays neutral with regard to jurisdictional claims in published maps and institutional affiliations.

Copyright: (c) 2021 by the authors. Licensee MDPI, Basel, Switzerland. This article is an open access article distributed under the terms and conditions of the Creative Commons Attribution (CC BY) license (https:/ / creativecommons.org/licenses/by/ $4.0 /)$.

\begin{abstract}
In this work, gold and bismuth bimetallic nanoparticles decorated L-cysteine functionalized graphene oxide nanocomposites ( $\mathrm{Au}-\mathrm{BiNPs} / \mathrm{SH}-\mathrm{GO}$ ) were prepared and applied to selective detection of Fe(III) in lake and seawater samples by modifying onto glassy carbon electrodes. Bimetallic nanoparticles have various excellent properties and better catalytic properties because of the unique synergistic effect between metals. The modified electrode was characterized by scanning electron microscopy, energy dispersive $\mathrm{X}$-ray spectroscopy, $\mathrm{X}$-ray diffraction, $\mathrm{X}$-ray photoelectron spectroscopy, Fourier transform infrared spectroscopy, and Raman spectroscopy. Under optimized conditions, current peak intensity increased linearly with increasing $\mathrm{Fe}(\mathrm{III})$ concentration over the range of $0.2-50 \mu \mathrm{M}$ and a detection limit of $0.07 \mu \mathrm{M}(\mathrm{S} / \mathrm{N}=3)$. The Au-BiNPs/SH-GO/GCE was used for the determination of $\mathrm{Fe}(\mathrm{III})$ in lake and seawater samples with recoveries ranged from 90 to $103 \%$. Those satisfactory results revealed the potential application of the Au-BiNPs/SH-GO electrochemical sensor for heavy metals detection in environmental monitoring.
\end{abstract}

Keywords: bimetallic; iron ions; gold; bismuth; graphene oxide; electrochemical sensor

\section{Introduction}

Iron is the fourth highest element in the crust with a total content of about $5 \%$ [1]. Iron is an indispensable micronutrient element in the growth of plants and animals [2-4]. Iron itself is not toxic, but it can cause iron poisoning with an overdose of iron preparations. Excessive Fe(III) solution in drinking water could lead to a lot of problems to the people's health. The suggested guideline level of iron ions in water is $0.3 \mathrm{ppm} \mathrm{[5].} \mathrm{Hence,} \mathrm{it} \mathrm{is}$ very important to study the iron ion detection problem in environmental water. Hence, iron ion levels are necessarily determined in different fields, such as clinical, drug, and environmental monitoring [6-12]. In the past few decades, a large number of methods have been developed and applied to detect iron ions, including flame atomic absorption spectrometry [13], inductively coupled plasma mass spectrometry [14], reversed-phase high-performance liquid chromatography [15], electrochemistry [16,17], colorimetric analysis [18-20], and fluorescent spectrophotometry [21-23]. Among these analytical methods, electrochemical analysis has attracted much attention owing to its simple and fast operation, high sensitivity and low cost [24].

In order to improve the selectivity and sensitivity of the electrode, the chemical modification of the electrode surface becomes the focus of interest in research [25]. The 
researchers used nanomaterials modified electrodes to construct electrochemical sensors, considering their unique surface effects, small size and excellent photoelectric properties. The large comparative area and strong adsorption properties of nanomaterials can achieve adsorption equilibrium with a short time in the detection of metal ions, which is conducive to the enrichment and detection of metal ions in solution.

In recent years, bimetallic nanoparticles have been widely studied because of their special catalysis, electrical and optical properties [26,27]. Unlike single nanomaterials, bimetallic nanoparticles have many more excellent properties than single component materials, which fills up the shortcomings of single component materials. In addition, bimetallic nanoparticles can produce comprehensive effects on the basis of maintaining their own excellent properties [28]. Gold and bismuth bimetallic nanoparticles (Au-BiNPs) have small nanometer size, strong catalytic performance and excellent dielectric properties. The properties of Au-BiNPs are better than those of gold or bismuth single nanoparticles, and they can form amalgam alloys like heavy metal ions [29]. Moreover, it has the advantages of low background current and good stability, which is beneficial to the high sensitivity analysis of heavy metal ions.

Graphene oxide (GO) has been widely used due to its unique structure, good electrical conductivity, strong mechanical properties, and large surface area [30,31]. Ding et al. functionalized graphene by introducing different metal nanoparticles or organic molecules on the surface of graphene to improve the detected effects of $\mathrm{Hg}$ (II) and $\mathrm{As}(\mathrm{II})[32,33]$. The functional groups on mercapto-modified graphene oxide (SH-GO) adsorb heavy metals by forming chelates with metal ions, which makes the nanoparticles loaded better and improves the electron transfer efficiency between materials and electrodes [34]. Sitko et al. [35] used quantitative adsorption of $\mathrm{Co}(\mathrm{II}), \mathrm{Ni}(\mathrm{II}), \mathrm{Cu}(\mathrm{II}), \mathrm{As}(\mathrm{III}), \mathrm{Cd}(\mathrm{II})$, and $\mathrm{Pb}$ (II) by the wrinkled structure of SH-GO nanosheets.

In this paper, gold and bismuth bimetallic nanoparticles decorated with L-cysteine functionalized graphene oxide nanocomposites (Au-BiNPs/SH-GO) were prepared and applied to selective detection of $\mathrm{Fe}(\mathrm{III})$ in lake and seawater samples by modifying them on a glassy carbon electrode using the square wave voltammetry method (SWV). The sensor is very prominent with low detection, high sensitivity, and wide linear range. The Au-BiNPs/SH-GO/GCE was also successfully applied for the detection of total dissolved iron ions in water samples with satisfactory results.

\section{Experimental Details}

\subsection{Materials}

L-cysteine, 3-ammonia propyl-3-ethoxy silane, $N, N^{\prime}$-dicyclohexylcarbodiimide (DCC), $\mathrm{N}, \mathrm{N}$-Dimethylformamide (DMF), potassium ferricyanide $\left(\mathrm{K}_{3}\left[\mathrm{Fe}(\mathrm{CN})_{6}\right]\right)$, potassium chloride $(\mathrm{KCl})$, and ethanol were purchased from Sinopharm Chemical Reagent Co., Ltd. (Beijing, China). Chloroauric acid $\left(\mathrm{HAuCl}_{4}\right)$, Bismuth nitrate pentahydrate $\left(\mathrm{BiNO}_{3} \cdot 5 \mathrm{H}_{2} \mathrm{O}\right)$ and Sodium borohydride $\left(\mathrm{NaBH}_{4}\right)$ were purchased from Medicine Group Chemical Reagent Co., Ltd. (Shanghai, China). GO was obtained from the XFNano Materials Technology Company (Nanjing, China). All chemicals were analytical grade and used as received. Ultrapure water $(18.2 \mathrm{M} \Omega \mathrm{cm})$ was used in all experiments.

\subsection{Apparatus}

Scanning electron microscopy (SEM) images were obtained using a field emission scanning electron microanalyzer (S-4800, Hitachi, Tokyo, Japan). Energy dispersive X-ray spectroscopy (EDX) was measured by EDX HORIBA EX-350. X-ray diffraction (XRD) measurements were obtained using an $X$-ray diffractometer to determine the crystal phase composition of the sample (XRD6000, Shimadzu, Tokyo, Japan). X-ray photoelectron spectra (XPS) analysis was tested with an ESCALAB 250Xi (Thermo, Waltham, MA, USA). All electrochemical experiments were carried out on a workstation (CHI660C, Shanghai Chenhua Instrument Co., Ltd., Shanghai, China). Bare or modified electrodes were used 
as working electrodes, and a $\mathrm{Pt}$ wire electrode was the auxiliary electrode. $\mathrm{An} \mathrm{Ag} / \mathrm{AgCl}$ (saturated $\mathrm{KCl}$ solution) was used as a reference electrode.

\subsection{Preparation of Au-BiNPs/SH-GO Nanomaterials}

The suspension of GO $(0.2 \mathrm{~g})$ in anhydrous ethanol $(30 \mathrm{~mL})$ was sonicated for $1 \mathrm{~h}$. Then, 3-ammonia propyl-3-ethoxy silane $(2 \mathrm{~mL})$ was added and refluxed at $70{ }^{\circ} \mathrm{C}$ for $8 \mathrm{~h}$. The obtained product was purified by anhydrous ethanol and dried for $10 \mathrm{~h}$. Moreover, the suspension of resulted powder $(0.2 \mathrm{~g})$ in DMF $(50 \mathrm{~mL})$ was sonicated for $15 \mathrm{~min}$ and DCC $(0.1 \mathrm{~g})$ with L-cysteine $(0.1 \mathrm{~g})$ was added to the suspension and refluxed at $70{ }^{\circ} \mathrm{C}$ for $24 \mathrm{~h}$. The obtained product was purified by anhydrous ethanol and dried for $10 \mathrm{~h}$ again. Finally, the material SH-GO was obtained [36].

The SH-GO was uniformly dispersed into DMF, then the aqueous solution of $\mathrm{BiNO}_{3} \cdot 5 \mathrm{H}_{2} \mathrm{O}$ and $\mathrm{HAuCl}_{4}$ was added and mixed. The final concentration of $\mathrm{Bi}(\mathrm{III})$ and $\mathrm{Au}(\mathrm{III})$ was $0.01 \mathrm{M}$. The content of $\mathrm{GO}$ was $1.5 \%$ of the content of $\mathrm{BiNO}_{3} \cdot 5 \mathrm{H}_{2} \mathrm{O}$ (weight percentage), and then the $\mathrm{pH}$ of the solution was adjusted by $\mathrm{NaOH}$ to 12 . The mixed solution was transferred to the reactor of PTFE by stirring for $30 \mathrm{~min}$, and the reaction was heated at $120^{\circ} \mathrm{C}$ for $12 \mathrm{~h}$. Finally, the nanocomposites were placed on the cold trap of the vacuum freeze dryer to pre freezing for $3 \mathrm{~h}$ at $-30^{\circ} \mathrm{C}$. Then, the frozen nanocomposites were put in a drying chamber with the chamber was evacuated less than $100 \mathrm{~Pa}$ for $8 \mathrm{~h}$.

\subsection{Electrode Preparation and Modification}

First, the GCE was polished with 0.5 and $0.05 \mu \mathrm{m}$ diameter alumina polishing powder. Then, the polished electrodes were then washed in ethanol and distilled water for $3 \mathrm{~min}$ and dried in air. Au-BiNPs/SH-GO $(2.0 \mathrm{mg})$ was dispersed in $1.0 \mathrm{~mL}$ of distilled water. The dispersed liquid droplets of $5.0 \mu \mathrm{L}$ nanomaterials were coated on the surface of GCE, and then dried under an infrared lamp for half an hour, rinsed with ultrapure water several times to obtain Au-BiNPs/SH-GO/GCE (Scheme 1). IR lamp was used for the nanocomposite drying fast and heating evenly on the electrode surface. The ultrapure water treatment was in order to remove excess unabsorbed nanomaterials. The mercaptomodified graphene oxide material modified GCE (SH-GO/GCE) and graphene oxide material modified GCE (GO/GCE) used the same method of preparation.

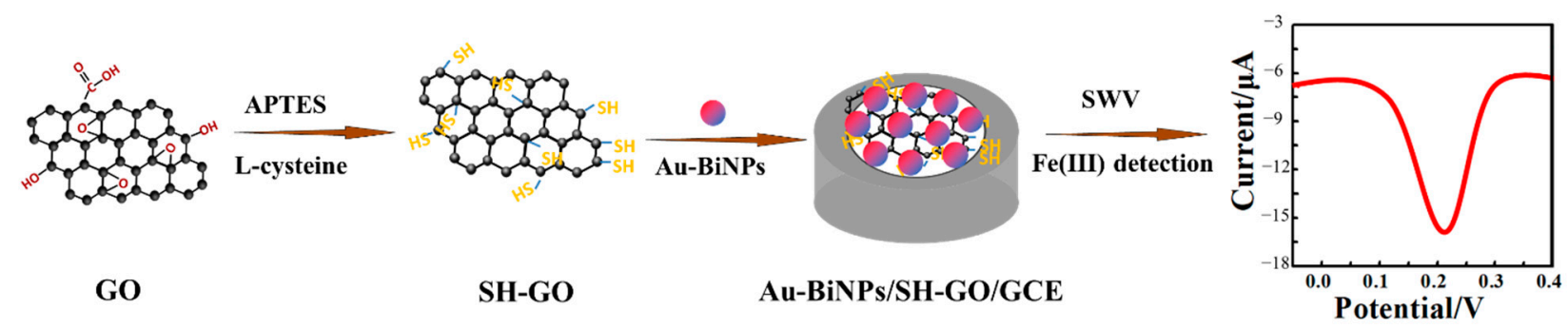

Scheme 1. Schematic diagram for the synthesis of Au-BiNPs/SH-GO/GCE and its application in detection of Fe(III).

\subsection{Electrochemical Detection Process}

The electrochemical detection process was carried out in $0.1 \mathrm{M} \mathrm{HCl}$ supporting electrolyte. SWV was used to detect the concentration of Fe(III) in the modified electrodes by measuring the reduction current of Fe(III) reduced to Fe(II) on the surface of the modified electrodes. In the detection process, the three-electrode system was inserted into the $\mathrm{Fe}(\mathrm{III})$ electrolyte containing a certain concentration. After enrichment, the negative sweep electrode potential of $\mathrm{Fe}(\mathrm{III})$ on $\mathrm{Au}-\mathrm{BiNPs} / \mathrm{SH}-\mathrm{GO} / \mathrm{GCE}$ was obtained under the potential window of -0.2 to $0.6 \mathrm{~V}$. The experimental parameters are as follows: the initial potential is $0.6 \mathrm{~V}$, the termination potential is $-0.2 \mathrm{~V}$, the amplitude is $0.025 \mathrm{~V}$, the frequency is $15 \mathrm{~Hz}$, and the equilibrium time is $2 \mathrm{~s}$. 


\section{Results and Discussion}

\subsection{Structural and Compositional Characterizations of Au-BiNPs/SH-GO/GCE}

The surface morphologies of the various modified electrodes were characterized by SEM and EDX (Figure 1). Compared with the surface of the GO/GCE (Figure 1A), SHGO/GCE (Figure 1B) surface showed more folds [37], and these large specific surface areas provide a larger adhesion area for the loading of metal nanoparticles. At the same time, it is also beneficial to the complete contact between electrolyte and electrode surface [38]. It is showed that SH-GO/GCE has been successfully combined with gold and bismuth nanoparticles (Figure 1C). SH-GO had lots of sulfhydryl groups and wrinkles to lead to strong chelation with Fe(III) [34], and the Au-BiNPs could combine with metal ions to form amalgam analogs [29]. The nanomaterial of SH-GO was combined with gold and bismuth nanoparticles not only provides a large specific surface area and binding sites but also improves the electrochemical signal for Fe(III) detection. Combined with the EDX analysis of Au-BiNPs/SH-GO/GCE in Figure 1D, the results showed that the main components of $\mathrm{Au}-\mathrm{BiNPs} / \mathrm{SH}-\mathrm{GO} / \mathrm{GCE}$ are four elements of $\mathrm{C}, \mathrm{O}, \mathrm{Au}, \mathrm{Bi}$. The $\mathrm{C}$ element mainly comes from the skeleton structure of $\mathrm{SH}-\mathrm{GO} / \mathrm{GCE}$, while the O element mainly comes from the oxygen-containing functional groups such as carboxyl, hydroxyl, epoxide, and carbonyl groups on the surface of SH-GO/GCE. Sulfur has a response signal in $2.4 \mathrm{KeV}$ [39], which may be covered by other signal peaks, so it needs to be analyzed by other characterization methods. However, a more detailed analysis of the chemical composition of the surface of $\mathrm{Au}-\mathrm{BiNPs} / \mathrm{SH}-\mathrm{GO} / \mathrm{GCE}$ and the presence of $\mathrm{C}, \mathrm{S}, \mathrm{Au}$, and Bi by elemental mapping taken with EDX is shown in Figure S1. Therefore, it is proved that the elements are uniformly distributed in the nanomaterials.
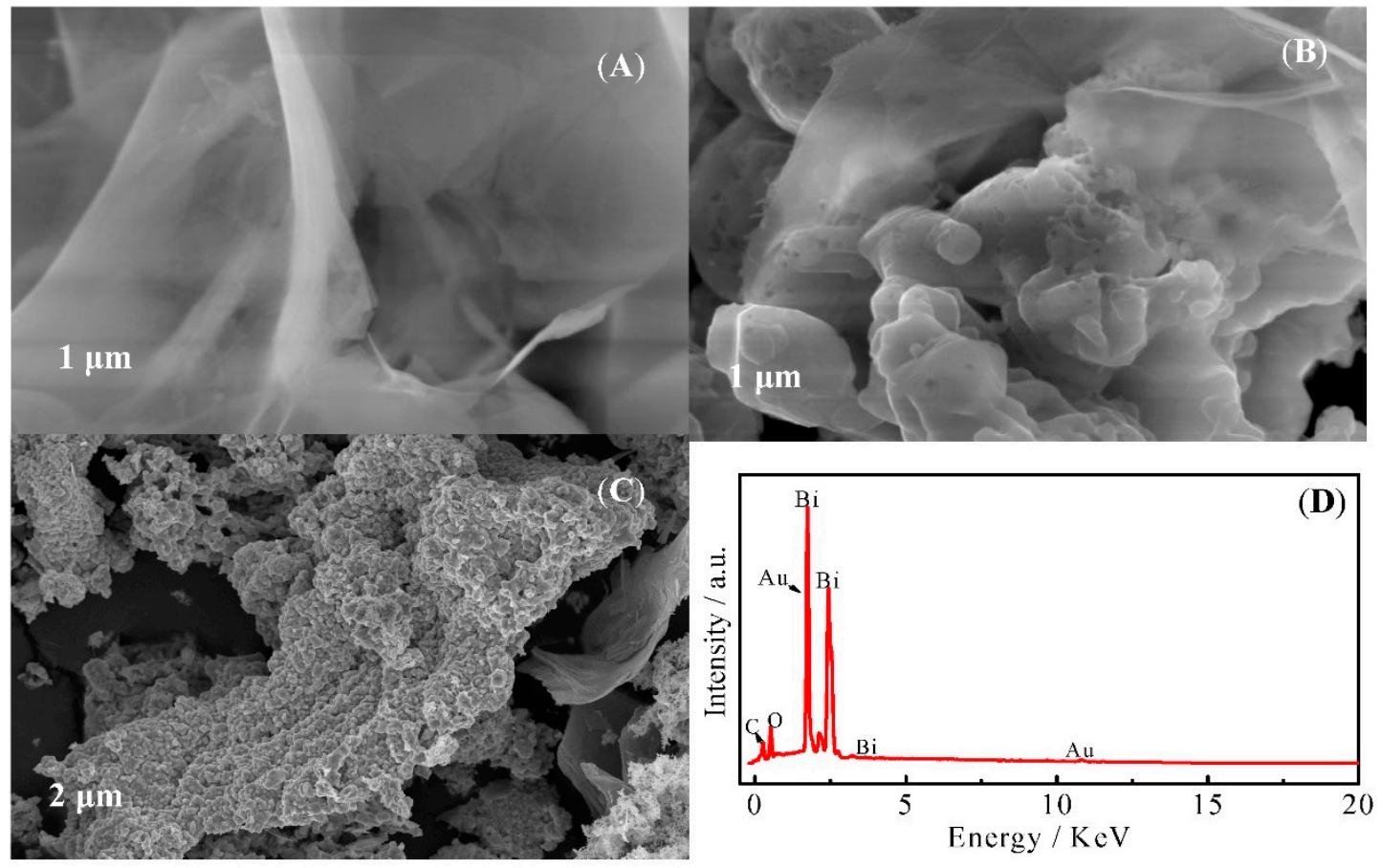

Figure 1. SEM images of (A) GO/GCE; (B) SH-GO/GCE and (C) Au-BiNPs/SH-GO/GCE; (D) EDX patterns of AuBiNPs/SH-GO/GCE.

Figure 2A shows the XRD spectra of SH-GO/GCE (a) and Au-BiNPs/SH-GO/GCE (b). Compared with the peak at $10.7^{\circ}$ of GO/GCE, the order of wide peak arrangement of SH-GO/GCE at $24.6^{\circ}$ was worse. The results showed that the elimination of functional groups leads to the decrease of layer spacing and the (200) plane is $\mathrm{S}$ crystal structure plane. The activity peak of Au-BiNPs/SH-GO/GCE at $10.7^{\circ}$ graphene is not obvious. These peaks at $27.2^{\circ}, 38.1^{\circ}$, and $39.7^{\circ}$ belong to the (012), (104), and (110) planes of the rhombohedral Bi 
crystal structure. In addition, the characteristic peaks at $44.4^{\circ}$ and $64.5^{\circ}$ were corresponding to (200) and (220) Au structure planes [40].
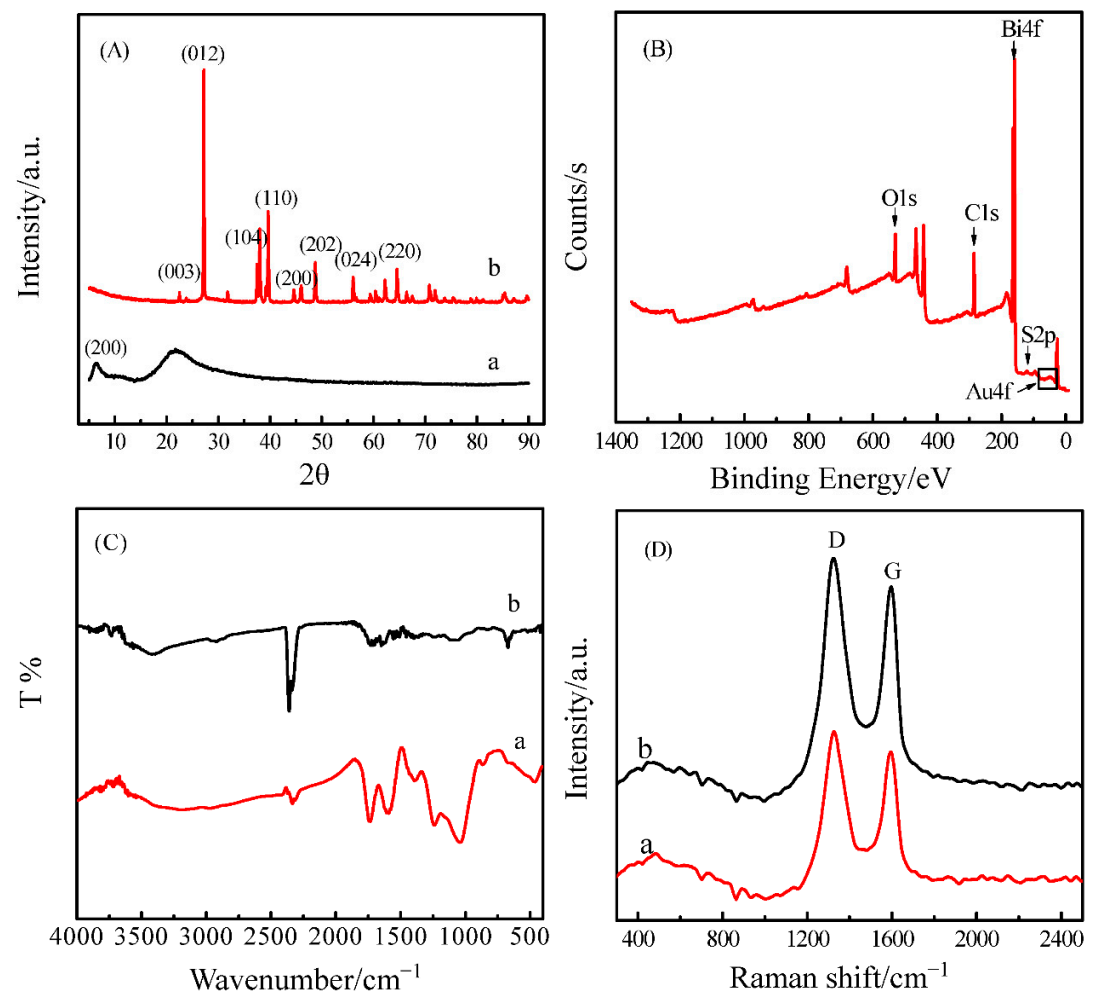

Figure 2. (A) XRD patterns of (a) SH-GO/GCE, (b) Au-BiNPs/SH-GO/GCE; (B) XPS survey spectrum of Au-BiNPs/SH-GO/GCE; (C) FT-IR spectra of (a) SH-GO/GCE, (b) Au-BiNPs/SH-GO/GCE; and (D) Raman spectra of (a) SH-GO/GCE, (b) Au-BiNPs/SH-GO/GCE.

XPS spectrum of Au-BiNPs/SH-GO/GCE (Figures 2B and S2) showed the existence of five elements, $\mathrm{C}, \mathrm{Au}, \mathrm{Bi}, \mathrm{S}$, and $\mathrm{O}$, respectively. Figure S2A showed the presence of three main types of carbon bonds of $\mathrm{C}-\mathrm{C}(284.7 \mathrm{eV}), \mathrm{C}-\mathrm{O}(285.6 \mathrm{eV})$ and $\mathrm{C}=\mathrm{O}(288.9 \mathrm{eV})$. As shown in Figure S2B, the peak at $84.0 \mathrm{eV}$ was caused by $\mathrm{Au}_{4} \mathrm{f}_{7 / 2}$, while the Au4f $\mathrm{f}_{5 / 2}$ signal peak appears at $87.76 \mathrm{eV}$. Meanwhile, the peak at $153.7 \mathrm{eV}$ and $157.7 \mathrm{eV}$ were caused by Bi4f (Figure S2C) and S2p (Figure S2D), respectively. The results confirm the presence of $\mathrm{Au}$, Bi nanoparticles and sulfhydryl group in the Au-BiNPs/SH-GO/GCE [41]. The XPS spectrum clearly evidenced the synthesis of Au-BiNPs/SH-GO nanocomposites.

The Fourier transform infrared spectra (FT-IR) are shown in Figure 2C. The peaks at $1734,1616,1390$ and $1050 \mathrm{~cm}^{-1}$ may be caused by the stretching vibration of $-\mathrm{COOH}$, $\mathrm{O}-\mathrm{H}, \mathrm{C}-\mathrm{OH}$, and $\mathrm{C}-\mathrm{O}-\mathrm{C}$ functional groups [42]. It is indicated that there are many oxygencontaining functional groups on the surface of SH-GO/GCE. In addition, the -COOH, $\mathrm{C}-\mathrm{OH}$, and $\mathrm{C}-\mathrm{O}-\mathrm{C}$ groups were also found in Au-BiNPs/SH-GO/GCE, but the peak of $\mathrm{C}-\mathrm{O}-\mathrm{C}$ was obviously weakened. It is clearly demonstrated that the formation of metal nanoparticles on graphene oxide lamellae can promote the reduction of graphene oxide.

At the same time, Raman spectroscopy was used to characterize the structure of Au-BiNPs/SH-GO/GCE (Figure 2D). Both SH-GO/GCE and Au-BiNPs/SH-GO/GCE have two distinct characteristic peaks. The $G$ peak near $1581 \mathrm{~cm}^{-1}$ is the characteristic peak of carbon $\mathrm{sp}^{2}$, which reflects its symmetry and degree of crystallization. The D peak near $1332 \mathrm{~cm}^{-1}$ is the defect peak, which reflects the disorder and defect degree of the graphite sheet. The $\mathrm{I}_{\mathrm{D}} / \mathrm{I}_{\mathrm{G}}$ value of Au-BiNPs/SH-GO/GCE (1.34) was higher than 0.97 of SH-GO/GCE, suggesting the generation of new quasi-amorphous $\mathrm{sp}^{2}$-bonded carbons. Combined with the above characterization methods, we successfully obtained Au-BiNPs/SH-GO nanocomposites. 


\subsection{Electrochemical Characterization of the AuNPs/SH-GO/GCE}

Several electrochemical techniques of cyclic voltammetry (CV) and electrochemical impedance spectroscopy (EIS) were applied to investigate the features of Au-BiNPs/SHGO/GCE. CV was implemented in $5 \mathrm{mM}\left[\mathrm{Fe}(\mathrm{CN})_{6}\right]^{3-/ 4-}$ containing $0.1 \mathrm{M} \mathrm{KCl}$, as shown in Figure 3A. Compared with the GCE and SH-GO/GCE, the redox peak currents of $\mathrm{Au}-\mathrm{BiNPs} / \mathrm{SH}-\mathrm{GO} / \mathrm{GCE}$ were, respectively increased about $35 \%$ and $25 \%$, indicating this sensor has better electrochemical catalytic sites and performance [43]. The results showed that $\mathrm{Au}-\mathrm{BiNPs} / \mathrm{SH}-\mathrm{GO} / \mathrm{GCE}$ has a better electronic response signal, which is beneficial to the determination of metal ions.
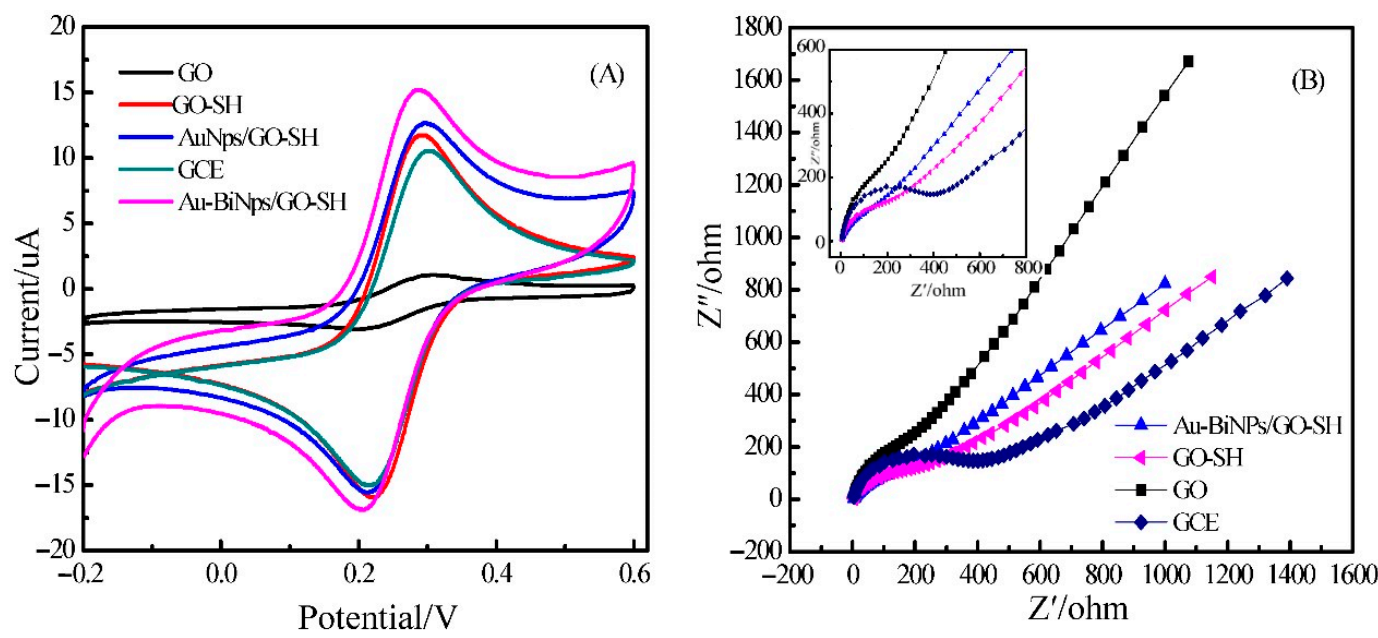

Figure 3. (A) CVs of different electrodes in $1 \mathrm{mM}\left[\mathrm{Fe}(\mathrm{CN})_{6}\right]^{3-/ 4-}$ solution containing $0.1 \mathrm{M} \mathrm{KCl}$ for GCE, GO/GCE, SH-GO/GCE, AuNPs/SH-GO/GCE and Au-BiNPs/SH-GO/GCE; (B) Nyquist plots of different electrodes in $1 \mathrm{mM}\left[\mathrm{Fe}(\mathrm{CN})_{6}\right]^{3-/ 4-}$ solution containing $0.1 \mathrm{M} \mathrm{KCl}$ for GCE, GO/GCE, SH-GO/GCE, AuNPs/SH-GO/GCE and Au-BiNPs/SH-GO/GCE.

The EIS curves are presented in Figure 3B. It is showed that the semicircle of the GCE electrode is slightly larger than that of the Au-BiNPs/SH-GO/GCE electrode, indicating that the charge transfer resistance on the Au-BiNPs/SH-GO/GCE electrode is smaller due to the modified metal nanoparticles increase the speed of electron transfer. The above results further prove that the charge transfer rate of $\mathrm{Au}-\mathrm{BiNPs} / \mathrm{SH}-\mathrm{GO} / \mathrm{GCE}$ electrode is higher than that of GCE, GO, and Au-BiNPs/SH-GO/GCE electrode.

\subsection{Optimization of Supporting Electrolytes}

$\mathrm{Fe}(\mathrm{III})$ is easy to hydrolyze under neutral or alkaline conditions, so the supporting electrolyte used to detect $\mathrm{Fe}$ (III) should be an acidic solution. In this experiment, HAc$\mathrm{NaAc}, \mathrm{H}_{2} \mathrm{SO}_{4}, \mathrm{HNO}_{3}$ and $\mathrm{HCl}$ with a concentration of $0.1 \mathrm{M}$ were selected as supporting electrolytes. The reduction current of Fe(III) in different electrolytes was investigated under the same experimental conditions. The experimental results show that $\mathrm{Fe}(\mathrm{III})$ has the largest current response in $\mathrm{HCl}$, followed by $\mathrm{H}_{2} \mathrm{SO}_{4}$, while the reduction peak current in $\mathrm{HAc}-\mathrm{NaAc}$ and $\mathrm{H}_{2} \mathrm{SO}_{4}$ is very small, as shown in Figure S3A. Finally, $\mathrm{HCl}$ was chosen as the supporting electrolyte because the $\mathrm{Cl}^{-}$in $\mathrm{HCl}$ could act as a salt bridge in the solution and accelerate the electron transfer between Fe(III) and electrode. In addition, different concentrations of $\mathrm{HCl}$ were optimized, as shown in Figure S3B. When the concentration of $\mathrm{HCl}$ was $0.1 \mathrm{M}$, the maximum current response signal is obtained. Therefore, $0.1 \mathrm{M} \mathrm{HCl}$ was chosen as the supporting electrolyte in this experiment.

\subsection{Electrochemical Sensing of Fe(III) on Au-BiNPs/SH-GO/GCE}

Under the optimum conditions, the standard iron ions solution was detected by SWV with Au-BiNPs/SH-GO/GCE modified electrode. Figure 4A shows typical SWV curves with a fast response performance. The electrode has a good linearity for the detection of $\mathrm{Fe}(\mathrm{III})$ in the range of $0.2 \mu \mathrm{M}$ to $50 \mu \mathrm{M}$. The linear regression equation (Figure $4 \mathrm{~B}$ ) is 
$\mathrm{I}(\mu \mathrm{A})=0.1191 c(\mu \mathrm{M})+7.764\left(\mathrm{R}^{2}=0.993\right)$ with the detection limit of $0.07 \mu \mathrm{M}(\mathrm{S} / \mathrm{N}=3)$. The results showed that the Au-BiNPs/SH-GO/GCE has a better sensitivity to the Fe(III). Compared with other previously reported sensors for Fe(III) detection (Table 1) [44-49], the proposed sensing platform processed more sensitivity and lower limit of detection.
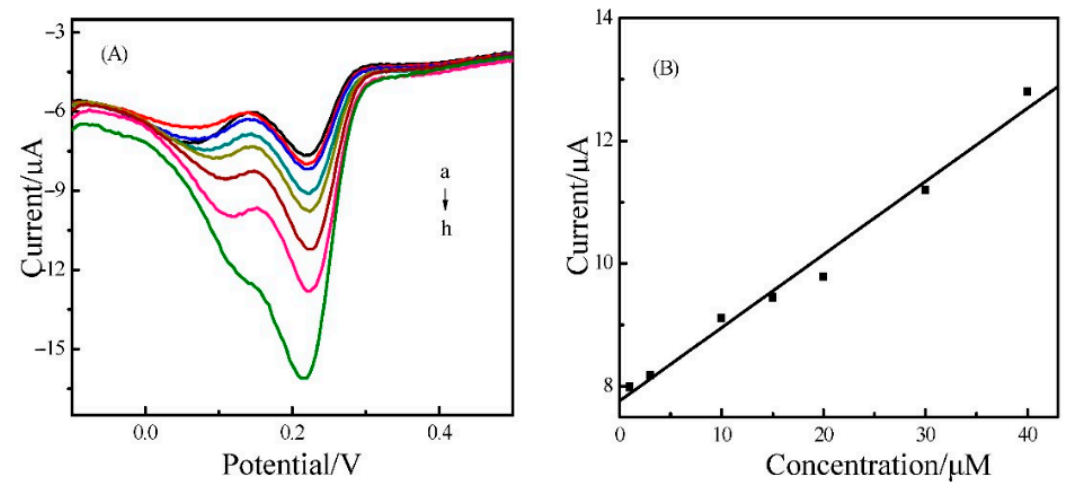

Figure 4. (A) SWV curves of Au-BiNPs/SH-GO/GCE in $0.1 \mathrm{M} \mathrm{HCl}$ containing different $\mathrm{Fe}(\mathrm{III})$ concentrations of $0.2,0.8,1,5,10,20,30$, and $50 \mu \mathrm{M}$ for a to h. (B) Linear plot of peak current versus $\mathrm{Fe}(\mathrm{III})$ concentration.

Table 1. Comparison of this work with previously reported Fe(III) detection methods.

\begin{tabular}{|c|c|c|c|}
\hline Modified Nanomaterials & Linear Range $(\mu \mathrm{M})$ & Detection Limit $(\mu \mathrm{M})$ & Ref. \\
\hline FAQT $^{a}$ & $5-100$ & 0.23 & [1] \\
\hline $\mathrm{P}(\mathrm{TPP}) \mathrm{b}$ & $0.1-100$ & 0.173 & [2] \\
\hline DPYBT $^{c}$ & $3.8-7.2$ & 3.04 & [3] \\
\hline GQD/PS-AER $^{\mathrm{d}}$ & $1-7$ & 0.65 & [4] \\
\hline CPB@PSAA e & $5-150$ & 2.2 & [5] \\
\hline AgNCs-PBH $^{f}$ & $0.14-27$ & 0.045 & [6] \\
\hline Au-BiNPs/SH-GO & $0.5-50$ & 0.07 & This work \\
\hline
\end{tabular}

$\overline{{ }^{a}}$ ferrocene appended quinoline-triazole; ${ }^{\mathrm{b}}$ pyrene-substituted poly(2,5-dithienylpyrrole); ${ }^{\mathrm{c}}$ 4,7-di-pyrrol-1-ylbenzo[1,2,5]thiadiazole; ${ }^{\mathrm{d}}$ graphene quantum dots/polystyrenic anion-exchange resin; ${ }^{\mathrm{e}} \mathrm{CsPbBr} 3$ perovskite quantum dots@poly(styrene/acrylamide); ${ }^{\mathrm{f}}$ silver nanoclusters@poly vinyl alcohol-borax hydrogel.

\subsection{Stability, Repeatability and Selectivity of the Sensor}

The stability, repeatability and selectivity of Au-BiNPs/SH-GO/GCE were also investigated. The stability of the electrode was measured 10 times by the same $\mathrm{Au}-\mathrm{BiNPs} / \mathrm{SH}$ GO/GCE electrode in Fe(III) $(1 \mu \mathrm{M})$ solution. The relative standard deviation (RSD) of the peak current was $1.67 \%$. The repeatability of the electrode was measured by 10 modified electrodes in $\mathrm{Fe}(\mathrm{III})(1 \mu \mathrm{M})$ solution revealed the RSD of $2.35 \%$. It is indicated that Fe(III) detection by Au-BiNPs/SH-GO/GCE has good stability and reproducibility.

Furthermore, the influence of common co-existing metal ions, such as $\mathrm{K}^{+}, \mathrm{Na}^{+}, \mathrm{Pb}^{2+}$, $\mathrm{Zn}^{2+}, \mathrm{Mn}^{2+}, \mathrm{Ca}^{2+}, \mathrm{Cu}^{2+}, \mathrm{Al}^{3+}, \mathrm{Mg}^{2+}$ on the detection of $\mathrm{Fe}(\mathrm{III})$ was tested under the optimized conditions. The results showed (Figure 5) that 50-fold concentrations of $\mathrm{Zn}^{2+}, \mathrm{Mn}^{2+}$, $\mathrm{Ca}^{2+}, \mathrm{Al}^{3+}$ and 100 -fold concentrations of $\mathrm{K}^{+}, \mathrm{Na}^{+}, \mathrm{Pb}^{2+}, \mathrm{Mg}^{2+}, \mathrm{Cu}^{2+}$ had no significant effect on the determination of Fe(III) when the concentration of Fe(III) was $1 \mu \mathrm{M}$. 


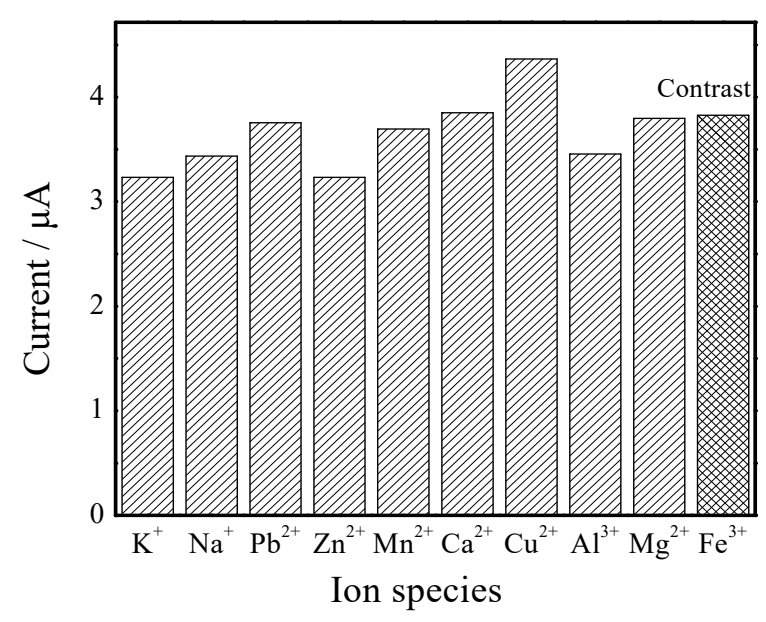

Figure 5. Effects of various interference metal ions on the electrochemical signals of Fe(III) at AuBiNPs/SH-GO/GCE in $0.1 \mathrm{M} \mathrm{HCl}$ containing $1 \mu \mathrm{M}$ Fe(III) in the presence of 50-fold concentrations of $\mathrm{Zn}^{2+}, \mathrm{Mn}^{2+}, \mathrm{Ca}^{2+}, \mathrm{Al}^{3+}$ and 100 -fold concentrations of $\mathrm{K}^{+}, \mathrm{Na}^{+}, \mathrm{Pb}^{2+}, \mathrm{Mg}^{2+}, \mathrm{Cu}^{2+}$.

\section{Detection Application in Lake Water and Seawater Samples}

The applicability of the sensor in lake and seawater samples was studied. All water samples were filtered with $0.45 \mu \mathrm{m}$ membrane filter and then digested by microwave. The water samples were diluted 10 times, then added to $0.1 \mathrm{M} \mathrm{HCl}$ for detection. The concentration of Fe(III) in water samples was obtained by the standard addition method. As shown in Table 2, it is found that the Fe(III) concentration measured by the sensor is in good agreement with the results of ICP-MS and the recoveries ranged between 93 and $103 \%$ with the RSD lower than $2.7 \%$. The results show that the sensor can be used for the daily monitoring of Fe(III) and has significant application prospects.

Table 2. Assay results of Fe(III) in samples of lake water and seawater.

\begin{tabular}{cccccc}
\hline Samples & Added $(\boldsymbol{\mu M})$ & $\begin{array}{c}\text { Detected } \\
(\boldsymbol{\mu M})\end{array}$ & $\begin{array}{c}\text { ICP-MS } \\
(\boldsymbol{\mu M})\end{array}$ & $\begin{array}{c}\text { Recovery } \\
(\mathbf{\%}, \boldsymbol{n}=\mathbf{5})\end{array}$ & $\begin{array}{c}\text { RSD } \\
\mathbf{( \% )}\end{array}$ \\
\hline \multirow{3}{*}{ Lake water } & 0 & $4.04 \pm 0.08$ & 4.10 & - & 1.98 \\
& 0.3 & $4.32 \pm 0.12$ & 4.42 & 93.3 & 2.77 \\
& 3 & $6.86 \pm 0.07$ & 7.01 & 94.0 & 1.02 \\
Seawater & 30 & $35.07 \pm 0.20$ & 35.33 & 103.4 & 0.57 \\
\hline & 0.3 & $2.15 \pm 0.03$ & 2.08 & - & 1.40 \\
& 3 & $2.42 \pm 0.04$ & 2.37 & 90.0 & 1.65 \\
& 30 & $31.87 \pm 0.64$ & 31.85 & 100.3 & 2.13 \\
\hline
\end{tabular}

\section{Conclusions}

An Au-BiNPs/SH-GO/GCE electrochemical sensor has been developed which could be used for the detection of Fe(III). These nanomaterials were characterized by SEM, EDX, XRD, XPS, FT-IR, Raman, CV, and EIS, demonstrating SH-GO could carry many mercapto groups and possess better stability and dispersibility than GO. Moreover, gold and bismuth bimetallic nanoparticles had excellent ability to absorb and detect Fe(III). Experimental results indicated that the Au-BiNPs/SH-GO/GCE sensor has beneficial properties of high sensitivity, excellent stability, and reproducibility. Au-BiNPs/SH-GO/GCE sensor is also used for the detection of Fe(III) in lake water and seawater samples with correct and reliable results. The nanocomposites can also be used in other areas with great potential for research in the future.

Supplementary Materials: The following are available online at https: / www.mdpi.com/article / 10.3390/nano11092386/s1, Figure S1: Elemental mapping of C, Au, S, and Bi element distribu- 
tion, respectively, Figure S2: XPS survey spectrum of (A) C1s (B) Au4f (C) Bi4f and (D) S2p, Figure S3: (A) SWV measurements of $5 \mu \mathrm{M}$ Fe(III) at Au-BiNPs/SH-GO/GCE in different electrolytes. $0.1 \mathrm{M} \mathrm{HAc}-\mathrm{NaAc}(\mathrm{a}), 0.1 \mathrm{M} \mathrm{HNO}_{3}$ (b), $0.1 \mathrm{M} \mathrm{H}_{2} \mathrm{SO}_{4}$ (c) and $0.1 \mathrm{M} \mathrm{HCl}$ (d); (B) Effect of the concentration of $\mathrm{HCl}$ solution on the peak of $\mathrm{Fe}(\mathrm{III})$ at Au-BiNPs/SH-GO/GCE.

Author Contributions: Conceptualization, X.Z. and X.W.; methodology, J.L.; software, S.W.; validation, N.Z., F.L. and X.W.; formal analysis, J.L.; investigation, N.Z.; resources, S.N.; data curation, N.Z.; writing-original draft preparation, N.Z.; writing—review and editing, X.Z.; supervision, S.Y.; project administration, X.Z.; funding acquisition, S.Y. All authors have read and agreed to the published version of the manuscript.

Funding: This research was funded by the National Natural Science Foundation of China, grant number 21778047, 21675138, 21705139; the Scientific Instrument Developing Project of the Chinese Academy of Sciences, grant number YJKYYQ20190035; Key Science and Technology Program of Yantai, grant number 2019XDHZ093.

Conflicts of Interest: The authors declare that there is no conflict of interest.

\section{References}

1. Wedepohl, K.H. The composition of the continental crust. Mineral. Mag. 1994, 58, 1217-1232. [CrossRef]

2. Martin, J.H.; Coale, K.H.; Johnson, K.S.; Fitzwater, S.E.; Gordon, R.M.; Tanner, S.J.; Hunter, C.N.; Elrod, V.A.; Nowicki, J.L.; Coley, T.L. Testing the iron hypothesis in ecosystems of the equatorial Pacific Ocean. Nature 1994, 371, 123-129. [CrossRef]

3. Lindsay, W.L.; Schwab, A.P. The chemistry of iron in soils and its availability to plants. J. Plant Nutr. 1982, 5, 821-840. [CrossRef]

4. Guerinot, M.L.; Yi, Y. Iron: Nutritious, noxious, and not readily available. Plant Physiol. 1994, 104, 815. [CrossRef]

5. Wang, B.; Yang, Q.; Guo, C.; Sun, Y.; Xie, L.H.; Li, J.R. Stable Zr(IV)-based metal-organic frameworks with predesigned functionalized ligands for highly selective detection of Fe(III) ions in water. ACS Appl. Mater. Interfaces 2017, 9, 10286-10295. [CrossRef]

6. Frias-Espericueta, M.; Voltolina, D.; Osuna-Lopez, J.B. Acute toxicity of cadmium, mercury, and lead to whiteleg shrimp (Litopenaeus vannamei) postlarvae. Environ. Contam. Toxicol. 2001, 67, 580-586. [CrossRef]

7. Yao, H.; Jin, L.; Sue, H.-J.; Sumi, Y.; Nishimura, R. Facile decoration of Au nanoparticles on reduced graphene oxide surfaces via a one-step chemical functionalization approach. J. Mater. Chem. A 2013, 1, 10783-10789. [CrossRef]

8. Henley, W.J.; Yin, Y. Growth and photosynthesis of marine Synechococcus (Cyanophyceae) under iron stress. J. Phycol. 1998, 34, 94-103. [CrossRef]

9. Oliveira, A.F.; Nobrega, J.A.; Fatibello-Filho, O. Asynchronous merging zones system: Spectrophotometric determination of Fe(II) and Fe(III) in pharmaceutical products. Talanta 1999, 49, 505-510. [CrossRef]

10. Carneiro, J.M.T.; Dias, A.C.B.; Zagatto, E.A.G.; Honorato, R.S. Spectrophotometric catalytic determination of Fe(III) in estuarine waters using a flow-batch system. Anal. Chim. Acta 2002, 455, 327-333. [CrossRef]

11. Safavi, A.; Abdollahi, H.; Sedaghatpour, F.; Nezhad, M.H. Indirect simultaneous kinetic determination of semicarbazide and hydrazine in micellar media by H-point standard addition method. Talanta 2003, 59, 147-153. [CrossRef]

12. Zolgharnein, J.; Abdollahi, H.; Jaefarifar, D.; Azimi, G. Simultaneous determination of Fe(II) and Fe(III) by kinetic spectrophotometric H-point standard addition method. Talanta 2002, 57, 1067-1073. [CrossRef]

13. Costa, R.C.d.; Araújo, A.N. Determination of Fe(III) and total Fe in wines by sequential injection analysis and flame atomic absorption spectrometry. Anal. Chim. Acta 2001, 438, 227-233. [CrossRef]

14. Grotti, M.; Soggia, F.; Ardini, F.; Frache, R. Determination of sub-nanomolar levels of iron in sea-water using reaction cell inductively coupled plasma mass spectrometry after $\mathrm{Mg}(\mathrm{OH})_{2}$ coprecipitation. J. Anal. At. Spectrom. 2009, 24, 522-527. [CrossRef]

15. Zheng, L.; Watson, D.; Tettey, J.; Clements, C. The determination of iron as its EDTA complex in Helix aspera by hydrophilic interaction liquid chromatography coupled to Fourier transform electrospray ionisation mass spectrometry. Talanta 2008, 76, 1165-1169. [CrossRef]

16. Hu, X.; Pan, D.; Lin, M.; Han, H.; Li, F. Graphene oxide-assisted synthesis of bismuth nanosheets for catalytic stripping voltammetric determination of iron in coastal waters. Microchim. Acta 2016, 183, 855-861. [CrossRef]

17. Caprara, S.; Laglera, L.M.; Monticelli, D. Ultrasensitive and fast voltammetric determination of iron in seawater by atmospheric oxygen catalysis in $500 \mu \mathrm{L}$ samples. Anal. Chem. 2015, 87, 6357-6363. [CrossRef] [PubMed]

18. You, G.R.; Park, G.J.; Lee, S.A.; Ryu, K.Y.; Kim, C. Chelate-type Schiff base acting as a colorimetric sensor for iron in aqueous solution. Sens. Actuat. B-Chem. 2015, 215, 188-195. [CrossRef]

19. Goel, A.; Umar, S.; Nag, P.; Sharma, A.; Kumar, L.; Hossain, Z.; Gayen, J.R.; Nazir, A. A dual colorimetric-ratiometric fluorescent probe NAP-3 for selective detection and imaging of endogenous labile iron(III) pools in C. elegans. Chem. Commun. 2015, 51, 5001-5004. [CrossRef]

20. Liu, J.M.; Wang, X.X.; Jiao, L.; Cui, M.L.; Lin, L.P.; Zhang, L.H.; Jiang, S.L. Ultra-sensitive non-aggregation colorimetric sensor for detection of iron based on the signal amplification effect of $\mathrm{Fe}^{3+}$ catalyzing $\mathrm{H}_{2} \mathrm{O}_{2}$ oxidize gold nanorods. Talanta 2013, 116, 199-204. [CrossRef] 
21. Singh, V.; Mishra, A.K. Green and cost-effective fluorescent carbon nanoparticles for the selective and sensitive detection of iron(III) ions in aqueous solution: Mechanistic insights and cell line imaging studies. Sens. Actuat. B-Chem. 2016, 227, 467-474. [CrossRef]

22. Qu, Z.; Li, P.; Zhang, X.; Han, K. A turn-on fluorescent chemodosimeter based on detelluration for detecting ferrous iron $\left(\mathrm{Fe}^{2+}\right)$ in living cells. J. Mater. Chem. B 2016, 4, 887-892. [CrossRef]

23. Kumar, P.; Kumar, V.; Gupta, R. Arene-based fluorescent probes for the selective detection of iron. RSC Adv. 2015, 5, 97874-97882. [CrossRef]

24. Pan, D.; Wang, Y.; Chen, Z.; Lou, T.; Qin, W. Nanomaterial/ionophore-based electrode for anodic stripping voltammetric determination of lead: An electrochemical sensing platform toward heavy metals. Anal. Chem. 2009, 81, 5088-5094. [CrossRef] [PubMed]

25. Shervedani, R.K.; Hatefi-Mehrjardi, A. Sensitive determination of iron(III) by gold electrode modified with 2-mercaptosuccinic acid self-assembled monolayer. Anal. Chim. Acta 2007, 601, 164-171. [CrossRef] [PubMed]

26. Son, S.U.; Jang, Y.; Park, J.; Na, H.B.; Park, H.M.; Yun, H.J.; Lee, J.; Hyeon, T. Designed synthesis of atom-economical Pd/Ni bimetallic nanoparticle-based catalysts for sonogashira coupling reactions. J. Am. Chem. Soc. 2004, 126, 5026-5027. [CrossRef]

27. Wang, D.; Li, Y. Bimetallic nanocrystals: Liquid-phase synthesis and catalytic applications. Adv. Mater. 2011, 23, 1044-1060. [CrossRef]

28. Wang, G.-H.; Hilgert, J.; Richter, F.H.; Wang, F.; Bongard, H.-J.; Spliethoff, B.; Weidenthaler, C.; Schüth, F. Platinum-cobalt bimetallic nanoparticles in hollow carbon nanospheres for hydrogenolysis of 5-hydroxymethylfurfural. Nat. Mater. 2014, 13, 293. [CrossRef] [PubMed]

29. Kim, D.; Resasco, J.; Yu, Y.; Asiri, A.M.; Yang, P. Synergistic geometric and electronic effects for electrochemical reduction of carbon dioxide using gold-copper bimetallic nanoparticles. Nat. Commun. 2014, 5, 4948. [CrossRef] [PubMed]

30. Chang, J.; Zhou, G.; Christensen, E.R.; Heideman, R.; Chen, J. Graphene-based sensors for detection of heavy metals in water: A review. Anal. Bioanal. Chem. 2014, 406, 3957-3975. [CrossRef]

31. Molina, J.; Cases, F.; Moretto, L. Graphene-based materials for the electrochemical determination of hazardous ions. Anal. Chim. Acta 2016, 946, 9-39. [CrossRef] [PubMed]

32. Ding, L.; Liu, Y.; Zhai, J.; Bond, A.M.; Zhang, J. Direct Electrodeposition of Graphene-Gold Nanocomposite Films for Ultrasensitive Voltammetric Determination of Mercury(II). Electroanalysis 2014, 26, 121-128. [CrossRef]

33. Dar, R.A.; Khare, N.G.; Cole, D.P.; Karna, S.P.; Srivastava, A.K. Green synthesis of a silver nanoparticle-graphene oxide composite and its application for As(III) detection. RSC Adv. 2014, 4, 14432-14440. [CrossRef]

34. Pan, F.; Chen, D.; Zhuang, X.; Wu, X.; Luan, F.; Zhang, S.; Wei, J.; Xia, S.; Li, X. Fabrication of gold nanoparticles/1-cysteine functionalized graphene oxide nanocomposites and application for nitrite detection. J. Alloys Compd. 2018, 744, 51-56. [CrossRef]

35. Sitko, R.; Janik, P.; Zawisza, B.; Talik, E.; Margui, E.; Queralt, I. Green approach for ultratrace determination of divalent metal ions and arsenic species using total-reflection X-ray fluorescence spectrometry and mercapto-modified graphene oxide nanosheets as a novel adsorbent. Anal. Chem. 2015, 87, 3535-3542. [CrossRef]

36. Fan, L.; Luo, C.; Sun, M.; Li, X.; Qiu, H. Highly selective adsorption of lead ions by water-dispersible magnetic chitosan/graphene oxide composites. Colloids Surf. B 2013, 103, 523-529. [CrossRef] [PubMed]

37. Amin, H.M.; El-Kady, M.F.; Atta, N.F.; Galal, A. Gold Nanoparticles Decorated Graphene as a High Performance Sensor for Determination of Trace Hydrazine Levels in Water. Electroanalysis 2018, 30, 1757-1766. [CrossRef]

38. Wang, H.; Bo, X.; Zhang, Y.; Guo, L. Sulfur-doped ordered mesoporous carbon with high electrocatalytic activity for oxygen reduction. Electrochim. Acta 2013, 108, 404-411. [CrossRef]

39. Bas, S.Z. Gold nanoparticle functionalized graphene oxide modified platinum electrode for hydrogen peroxide and glucose sensing. Mater. Lett. 2015, 150, 20-23. [CrossRef]

40. Yu, H.; Xu, P.; Lee, D.-W.; Li, X. Porous-layered stack of functionalized AuNP-rGO (gold nanoparticles-reduced graphene oxide) nanosheets as a sensing material for the micro-gravimetric detection of chemical vapor. J. Mater. Chem. A 2013, 1, 4444-4450. [CrossRef]

41. Zhou, J.; Chen, M.; Diao, G. Assembling gold and platinum nanoparticles on resorcinarene modified graphene and their electrochemical applications. J. Mater. Chem. A 2013, 1, 2278-2285. [CrossRef]

42. Zhou, Q.; Zhang, Y.; Peng, H.F.; Ke, C.H.; Huang, H.Q. Toxicological responses of the hard clam Meretrix meretrix exposed to excess dissolved iron or challenged by Vibrio parahaemolyticus. Aquat. Toxicol. 2014, 156, 240-247. [CrossRef] [PubMed]

43. Yan, X.; Gu, Y.; Li, C.; Zheng, B.; Li, Y.; Zhang, T.; Zhang, Z.; Yang, M. Morphology-controlled synthesis of Bi ${ }_{2} \mathrm{~S}_{3}$ nanorods-reduced graphene oxide composites with high-performance for electrochemical detection of dopamine. Sens. Actuat. B-Chem. 2018, 257, 936-943. [CrossRef]

44. Kamal, A.; Kumar, S.; Kumar, V.; Mahajan, R.K. Selective sensing ability of ferrocene appended quinoline-triazole derivative toward Fe (III) ions. Sens. Actuat. B-Chem. 2015, 221, 370-378. [CrossRef]

45. Ayranci1, R.; Ak, M. An electrochemical sensor platform for sensitive detection of iron (III) ions based on pyrene-substituted poly(2,5-dithienylpyrrole). J. Electrochem. Soc. 2019, 166, B291-B296. [CrossRef]

46. Qian, J.; Huang, N.; Lu, Q.; Wen, C.; Xia, J. A novel D-A-D-typed rod-like fluorescent material for efficient Fe(III) and Cr(VI) detection: Synthesis, structure and properties. Sens. Actuat. B-Chem. 2020, 320, 128377. [CrossRef] 
47. Zhang, W.; Gan, J. Synthesis of blue-photoluminescent graphene quantum dots/polystyrenic anion-exchange resin for Fe(III) detection. Appl. Surf. Sci. 2016, 372, 145-151. [CrossRef]

48. Chen, M.; An, J.; Hu, Y.; Chen, R.; Lyu, Y.; Hu, N.; Luo, M.; Yuan, M.; Liu, Y. Swelling-shrinking modified hyperstatic hydrophilic perovskite polymer fluorescent beads for Fe(III) detection. Sens. Actuat. B-Chem. 2020, 325, 128809. [CrossRef]

49. Pourreza, N.; Ghomi, M. In situ synthesized and embedded silver nanoclusters into poly vinyl alcohol-borax hydrogel as a novel dual mode "on and off" fluorescence sensor for Fe (III) and thiosulfate. Talanta 2018, 179, 92-99. [CrossRef] 